\title{
Impact of a Novel Wellness Group Visit Model on Obesity and Behavior Change
}

\author{
Karen Axten, BA, Kerri Hawkins, RD, CPT, David J. Tybor, PhD, MPH, \\ Josh Bernoff, BS, and Wayne Altman, MD, FAAFP
}

Background: Increasing weight-related illness in the United States has led to 120,000 preventable deaths annually and soaring medical costs. Treating patients in a group setting may be more effective than traditional care (TC) in achieving behavioral change. We studied a wellness-group (WG) model to determine whether it could generate sustained behavioral change and weight loss in a subset of patients.

Methods: 99 patients with a body mass index (BMI) $>30 \mathrm{~kg} / \mathrm{m}^{2}$ from 1 family practice volunteered to participate in a 15-visit WG co-led by a family physician and dietitian. We compared these WG patients with 190 patients who had a BMI $>30 \mathrm{~kg} / \mathrm{m}^{2}$ and who received TC in the form of an annual physical during the same time period. The patients were mostly white, highly educated, and of middle-to-highincome households. All patients were surveyed on their ability to sustain 12 wellness behaviors 3 months after completing their WG or physical. Patients were not paid to complete the survey. We reviewed medical charts for weight, BMI, blood pressure, lipids, and glycohemoglobin before and at least 1 year after the WG or physical. WG patients' weights were recorded at the beginning and end of the WG as was the weight from their most recent office visit.

Results: WG patients were more likely to report sustaining 12 of 12 wellness behaviors than patients who received TC with an annual physical. At 1 year, WG patients also lost more weight than TC patients $(-13.21$ pounds for WG vs +1.94 pounds for TC) and achieved greater reduction in their systolic blood pressure (-6.96 $\mathrm{mm} \mathrm{Hg}$ for WG vs $\mathbf{- 1 . 1 3} \mathrm{mm} \mathrm{Hg}$ for TC). Average weight gained after the WG was 6.9 pounds. Among WG patients, $61 \%$ lost a clinically relevant amount of weight $(>5 \%)$. of the WG patients who lost clinically relevant weight, $71 \%$ were able to maintain at least half of their weight loss 3 years later.

Conclusions: An observational study of a novel WG model showed that WG patients sustained wellness behaviors and weight loss over time when compared with patients who received TC. (J Am Board Fam Med 2017;30:715-723.)

Keywords: Behavioral Counseling, Obesity

Over one third of US adults are obese and 3 out of 4 US adults are overweight or obese, leading to over 120,000 preventable deaths in the United States each year. ${ }^{1}$ Treatment of weight-related illnesses such as hypertension, high cholesterol, heart

This article was externally peer reviewed.

Submitted 1 March 2017; revised 23 July 2017; accepted 1 August 2017.

From the Department of Family Medicine (KA, KH, JB, WA), Department of Public Health and Community Medicine (DJT), Tufts University School of Medicine (TUSM), Boston, MA.

Funding: none.

Conflict of interest: none declared.

Corresponding author: Wayne Altman, MD, FAAFP, Department of Family Medicine, 200 Harrison Avenue, Boston, MA 02111 (E-mail: wayne.altman@tufts.edu). disease, type 2 diabetes, chronic pain, and depression in the primary care setting has led to soaring medical costs. ${ }^{2}$ Greater access to health care following passage of the Affordable Care Act, coupled with an ongoing shortage of primary care physicians, has increased the challenge of caring for chronic disease and obesity, exacerbated by the common patient-provider model. ${ }^{3}$ Fifteen-minute appointments often do not allow for a comprehensive, multifaceted approach to weight loss and behavioral change, and do not permit time to focus on the patient empowerment that is needed if health care providers want to reduce the morbidity and mortality of their overweight and obese patients. ${ }^{4}$ Stemming the epidemic of obesity will require in- 
novation within the field of primary care as traditional clinical approaches and commercial weight loss programs have had limited effectiveness.

In a systematic review of weight-loss interventions focusing on diet and lifestyle including 16 studies and 5698 subjects, the average weight lost was only $3.5 \mathrm{~kg}$ at 2 to 3 years. No studies in this review reported results of weight loss $\geq 5 \%$. With regard to more mainstream weight-loss programs, 1 study reviewed the effectiveness of Atkins, Ornish, Zone, and Weight Watchers diets on weight loss. This study found that in all 4 diets, only approximately $25 \%$ of participants lost $>5 \%$ and sustained it for up to a year. In each diet category, only approximately $10 \%$ of participants lost $>10 \%$ of body weight. Interestingly, there were no significant differences in effectiveness with weight loss between the 4 diets in this study. In another study, weight loss among participants enrolled onto interventions in a primary care practice using motivational interviewing was analyzed. Approximately $5 \%$ of weight was lost on average at 24 months. Lastly, a review investigating the effect of brief primary-care counseling alone found weight loss ranged from 0.1 to $2.3 \mathrm{~kg}$ after 1 year. ${ }^{5,6,7}$

The group visit model is a different approach to achieving weight loss. Group visits were first conceived in 1974 for use in well-child visits. ${ }^{8}$ This model is an alternative to back-to-back medical appointments for providers who seek efficiency, clinical effectiveness, and work satisfaction. ${ }^{9}$ Approximately $10 \%$ of the members of the American Academy of Family Physicians use group visits. ${ }^{10}$ This allows physicians to see more patients in a fixed period of time, and provides a new model for delivering effective care. For the physician, group visits provide the time necessary to share the educational tools needed for patients to be successful managers of their own health. For the patient, the group setting provides a built-in support network of peers who have similar health struggles. This "group effect" equips patients with an important sense of support, self-efficacy, and accountability that can translate into real results. ${ }^{11}$ In 1 randomized trial, group visit patients had greater reductions in systolic blood pressure and low-density lipoprotein (LDL) and fewer hospital admissions than traditional care (TC) patients. ${ }^{12}$ Given that obesity coexists with many chronic illnesses, an approach that starts with novel techniques to promote wellness and long-term weight loss is ideal.
One such approach is a group visit model that employs the expertise of both a family physician and a registered dietitian in helping patients change behavior and lose weight. Although the primary care field has begun to embrace the group visit model for management of chronic disease, there is scant research on how group visits can both help patients lose weight and keep weight off successfully. ${ }^{13-16}$ A systematic review of the literature by Edelman et $\mathrm{al}^{17}$ show that group visits reliably improve intermediate clinical outcomes for patients with type 2 diabetes. Although there is literature touting the benefits of group visits, we did not find any data on this novel group-visit model pairing a family physician and a dietitian.

Using a quasi-experimental study design, we compared the success of obese patients who volunteered to participate in a wellness group (WG) to obese patients who received TC from their physicians, testing changes in patients' behaviors, weight loss, blood pressure, lipids, and blood sugar, as well as the sustainability of these changes.

\section{Method \\ Setting}

This observational study was conducted at an outpatient family medicine office, Family Practice Group (FPG), in Arlington, Massachusetts, a suburb of Boston. The vast majority of patients at this practice are English speaking. Approximately 80\% of patients at this practice are privately insured. Approximately $20 \%$ of patients have Medicare or Medicaid.

\section{Patient Selection}

Providers in the practice (5 family physicians, 3 family physician assistants) recommended that their patients join the WG if they were obese (body mass index $[\mathrm{BMI}] \geq 30 \mathrm{~kg} / \mathrm{m}^{2}$ ) and if they were interested in losing weight and learning and maintaining healthy lifestyle habits. There were no other exclusion or inclusion criteria. We did not keep track of how many patients were encouraged to participate in the WG or the percentage of those patients receiving this recommendation who went on to participate in the group. Less than $10 \%$ of patients were referred to the WG by other primary care physicians in the surrounding area due to word of mouth from patients who had previously completed the group. 


\section{Intervention}

FPG started offering group visits in September 2009. The model was based on creating high levels of support and accountability for patients. The WG is led by a family physician and registered dietitian and consists of 15 evening group sessions over 20 weeks that focus on general wellness and sustained weight loss. Each group has between 6 and 15 patients who share the same goals of sustained weight loss and healthy living. Every fall (from September to January) and spring (from January to June), groups meet. The WG providers conduct 2 sessions per evening for 2 separate groups (6:00 to 7:30 pm and 7:30 to 9:00 pm). The groups follow a curriculum that focuses on 5 important dimensions of wellness: food quality, food quantity, exercise, activity, and sleep (WellnessCampaign.org). The physician and dietitian enter patients onto a group e-list and encourage group members to communicate with each other by email on a regular basis to create increased support and accountability. The 2 groups occur over the same 20-week period and compete for the highest average percentage weight loss. At the end, the group with the highest average percentage weight loss enjoys a healthy meal prepared by the other group.

\section{Study Design and Data Collection}

We compared patients in the WG to a comparison group of patients from the same practice who received TC. The TC group included patients with a BMI $\geq 30 \mathrm{~kg} / \mathrm{m}^{2}$ who had an annual physical over a 6 -year period. These patients were randomly chosen and then age- and sex matched to the WG patients (Table 1).

We designed a survey to assess behavioral change. The survey asked a series of questions regarding behaviors related to food quality, food quantity, exercise, activity, sleep, and stress; and, whether these behaviors were different 3 months after the intervention (WG or annual physical) compared with before the intervention. Respondents answered each question on a 5-point Likert scale between "strongly disagree" and "strongly agree." The patients were emailed the questionnaires by research staff and were reminded twice over the course of 3 weeks to complete the voluntary survey. Survey responses were anonymous so it was not possible to link survey data to medical chart data.

We obtained the following medical chart data for each patient: weight, BMI, blood pressure, gly-
Table 1. Demographics of Survey Respondents

\begin{tabular}{|c|c|c|}
\hline & WG & $\begin{array}{l}\text { Comparison } \\
\text { Group }\end{array}$ \\
\hline \multicolumn{3}{|l|}{ Race } \\
\hline Caucasian & 75 & 62 \\
\hline Asian & 5 & 5 \\
\hline African American & 1 & 3 \\
\hline \multicolumn{3}{|l|}{ Education } \\
\hline $\begin{array}{l}\text { High school diploma or } \\
\text { equivalent }\end{array}$ & 2 & 6 \\
\hline Associate's degree & 10 & 6 \\
\hline $\begin{array}{l}\text { Some college, no } \\
\text { degree }\end{array}$ & 4 & 10 \\
\hline Bachelor's degree & 26 & 16 \\
\hline Master's degree & 25 & 24 \\
\hline $\begin{array}{l}\text { Doctoral or } \\
\text { professional degree }\end{array}$ & 16 & 8 \\
\hline \multicolumn{3}{|l|}{ Marital status } \\
\hline Married & 61 & 54 \\
\hline Divorced/separated & 8 & 7 \\
\hline Single & 10 & 11 \\
\hline \multicolumn{3}{|l|}{ Income } \\
\hline Less than $\$ 25,000$ & 2 & 3 \\
\hline$\$ 25,000$ to $\$ 49,999$ & 8 & 12 \\
\hline$\$ 50,000$ to $\$ 74,999$ & 9 & 8 \\
\hline$\$ 75,000$ to $\$ 99,999$ & 14 & 7 \\
\hline$\$ 100,000$ to $\$ 149,999$ & 16 & 18 \\
\hline$\$ 150,000$ to $\$ 249,999$ & 26 & 12 \\
\hline$\$ 250,000$-to $\$ 499,999$ & 12 & 4 \\
\hline$\$ 500,000$ or more & 0 & 1 \\
\hline Kids at home (average) & 0.58 & 0.87 \\
\hline
\end{tabular}

WG, wellness group.

cohemoglobin, high-density lipoprotein (HDL), LDL, total cholesterol, and total triglycerides. We obtained data from 2 different time points. The first value was from the date of the intervention (the date of the patient's first WG session or the date of annual physical for the comparison group). The second value was the most recent data, at least 12 months postintervention. All the data were housed in a password-protected database for use only by research staff.

We measured the weight of all WG patients on the day they started the group, their weight on the day they completed the group, and their most upto-date weight from the last time they visited the physician's office. WG patients were also subdivided into 2 groups: those who completed only 1 group and those who completed multiple groups to compare long-term weight loss in these 2 populations. Losing $5 \%$ of body weight was considered 
clinically relevant weight loss. Patients were evaluated at 3 time intervals: 1 year, 2 years, and 3 years after completing group.

\section{Statistical Methods}

For the survey component of the study, we fit ordinal logistic regression models to compare responses between the WG patients and TC patients for each survey question, including interaction terms to investigate whether response patterns differed for potential effect modifiers, including sex, age, race, marital status, parenting status, education level, and income. For the medical chart review component of the study, we used independent sample $t$-tests to compare the mean change in weight, BMI, blood pressure, glycohemoglobin, HDL, LDL, total cholesterol, and triglycerides between the 2 groups of patients. To adjust for potential confounding by baseline BMI, for each of these outcomes we constructed a multiple linear regression model comparing the outcome between the 2 groups with baseline BMI as a covariate. We conducted all analyses with Stata v13 (StataCorp LLC, College Station, TX) using 2-sided tests with an $\alpha$ level of 0.05 .

\section{Results}

For the survey component of the study, the treatment group consisted of 99 patients who had an initial $\mathrm{BMI} \geq 30 \mathrm{~kg} / \mathrm{m}^{2}$ and had participated in the WG. The comparison group consisted of 190 patients who are patients of FPG, had received an annual physical at FPG sometime between September 2009 and January 2015, and who had an initial $\mathrm{BMI} \geq 30 \mathrm{~kg} / \mathrm{m}^{2}$.

Although all 99 WG patients were emailed the survey, 83 patients volunteered to complete the survey. Of these 83 patients, 2 patients filled out the survey incorrectly and were disqualified from the study. As a result, 81 patients served as the treatment group ( $81.8 \%$ of those targeted). These 81 patients completed the survey between 3 months and 5 years after completing the WG. Similarly, the comparison group consisted of the 190 FPG patients who had received an annual physical and whose $\mathrm{BMI} \geq 30 \mathrm{~kg} / \mathrm{m}^{2}$. Of these 190 patients, 135 had email addresses on file and were emailed the survey; 72 patients volunteered to complete the survey and served as the comparison group (53.3\% of those targeted). These 72 patients completed the survey between 3 months and 5 years after their annual physical.
For the weight change analysis, there were 168 patients in this data set as the analysis was done 1 year after the survey and chart review, so more patients had completed the WG by this time.

The survey revealed that members of the treatment group were significantly more likely to report that they were engaging in all 12 of the healthy habits we asked about compared with members of the comparison group 3 months after the intervention (Table 2). We assessed the amount of effort patients were putting into improving their health through lifestyle modification during the year before the intervention and found that members of the comparison group reported greater effort aimed toward wellness than members of the treatment group before the intervention (Table 2).

Some subgroups within the treatment group were more successful than others at practicing certain healthy habits. Married individuals were significantly more likely than nonmarried individuals to take more daily steps, eat more homecooked meals, and eat less beef 3 months after completion of the WG. Individuals over the age of 50 were significantly more likely to eat less beef than younger individuals, and individuals with children at home were significantly more likely to engage in frequent exercise 3 months after the intervention than individuals without children. These 5 findings came from formal statistical analysis of the interactions (data not shown here).

In the medical chart review, the treatment group consisted of 99 patients ( $57 \%$ women) with BMI $\geq 30 \mathrm{~kg} / \mathrm{m}^{2}$ who had completed the WG between September 2009 and January of 2015. On average, these patients attended $86 \%$ of the 15 group visit sessions in the program. The comparison group consisted of 190 patients who were patients of FPG (59\% women), had received an annual physical at FPG sometime between September 2009 and January 2015 and who had an initial BMI of $\geq 30$ $\mathrm{kg} / \mathrm{m}^{2}$. WG patients had an average BMI of 37 $\mathrm{kg} / \mathrm{m}^{2}$ whereas comparison group patients had an average BMI of $34 \mathrm{~kg} / \mathrm{m}^{2}$ (Table 3 ).

Relative to the comparison group, WG patients had significantly larger average declines in body weight, BMI, and systolic blood pressure 1 year after the intervention (Table 4). There was not a significant difference in average change in diastolic blood pressure, glycohemoglobin, HDL, LDL, total cholesterol, or triglycerides (Table 4). 
Table 2. Treatment Group Relative to Comparison Group Differences in Retrospective Self-Reported 3-Month Behavior Change, Ordinal Logistic Regression (Dependent Variable Likert Scale 1 to 5)

\begin{tabular}{lcc}
\hline Survey Question & $\begin{array}{c}\text { Odds Ratio For Treatment Group } \\
\text { Relative to Comparison Group } \\
\text { (95\% CI) }\end{array}$ & $P$ Value \\
\hline Read nutrition facts on food labels & $13.8(6.7$ to 28.6$)$ & $<.05$ \\
Eat more fruits and vegetables & $7.2(3.7$ to 14.2$)$ & $<.05$ \\
Feel "stuffed" less often & $6.6(3.4$ to 13.0$)$ & $<.05$ \\
Walk more steps daily & $5.3(2.8$ to 10.2$)$ & $<.05$ \\
Eat more whole grains & $4.8(2.5$ to 9.0$)$ & $<.05$ \\
Incorporate stress management & $4.4(2.3$ to 8.4$)$ & $<.05$ \\
Increase hours of sleep & $4.2(2.1$ to 8.4$)$ & $<.05$ \\
Eat less beef & $4.2(2.2$ to 8.3$)$ & $<.05$ \\
Eat less frequently in front of screens & $2.7(1.4$ to 5.3$)$ & $<.05$ \\
Eat more slowly & $2.7(1.4$ to 5.1$)$ & $<.05$ \\
Exercise more & $2.6(1.4$ to 4.7$)$ & $<.05$ \\
Eat more home-cooked meals & $1.9(1.1$ to 3.5$)$ & \\
Put effort into improving health before intervention & $0.5(0.3$ to 0.9$)$ & \\
\hline
\end{tabular}

CI, confidential interval.

Of the 168 patients who completed the WG between 2009 and 2014, the average total weight loss was 16.6 pounds, and $61 \%$ of all patients lost at least $5 \%$ of their initial body weight. Among those with clinically relevant weight loss during the program (at least $5 \%$ of initial body weight), 69\% maintained at least half of their weight loss 1 year later, and $71 \%$ were able to maintain at least half of their weight loss after 3 years. Patients who participated in more than $1 \mathrm{WG}$ were more likely to maintain weight loss; but even among those pa- tients who attended only 1 program, 54\% of those who lost clinically relevant weight were able to maintain at least half of their weight loss (Table 5 and Figure 1).

\section{Discussion}

The results of this study suggest that this novel group visit model teaming a family physician with a dietitian can help obese patients create and sustain a multitude of healthy behaviors long term.

Table 3. Demographics and Baseline Numbers of the Treatment and Comparison Groups Pertaining to Medical Chart Data

\begin{tabular}{|c|c|c|c|c|}
\hline & \multicolumn{2}{|c|}{ WG $(\mathrm{n}=99)$} & \multicolumn{2}{|c|}{ Comparison Group $(\mathrm{n}=190)$} \\
\hline & Male & Female & Male & Female \\
\hline Age (years) & 50.31 & 53.63 & 49.79 & 51.62 \\
\hline Sex & $\mathrm{N}=43$ & $\mathrm{~N}=56$ & $\mathrm{~N}=78$ & $\mathrm{~N}=112$ \\
\hline BMI $\left(\mathrm{kg} / \mathrm{m}^{2}\right)$ & 37.64 & 35.43 & 33.86 & 33.68 \\
\hline Weight (pounds) & \multicolumn{2}{|c|}{229.70} & \multicolumn{2}{|c|}{212.05} \\
\hline SBP (mm Hg) & \multicolumn{2}{|c|}{130.07} & \multicolumn{2}{|c|}{123.55} \\
\hline DBP (mm Hg) & \multicolumn{2}{|c|}{79.84} & \multicolumn{2}{|c|}{78.51} \\
\hline A1c (\%) & \multicolumn{2}{|c|}{6.35} & \multicolumn{2}{|c|}{5.85} \\
\hline HDL (mg/dL) & \multicolumn{2}{|c|}{51.17} & \multicolumn{2}{|c|}{55.03} \\
\hline $\mathrm{LDL}(\mathrm{mg} / \mathrm{dL})$ & \multicolumn{2}{|c|}{108.11} & \multicolumn{2}{|c|}{118.96} \\
\hline Total cholesterol (mg/dL) & \multicolumn{2}{|c|}{190.54} & \multicolumn{2}{|c|}{201.68} \\
\hline Triglycerides (mg/dL) & \multicolumn{2}{|c|}{173.95} & \multicolumn{2}{|c|}{154.59} \\
\hline
\end{tabular}

BMI, body mass index; DBP, diastolic blood pressure; HDL, high-density lipoprotein; LDL, low-density lipoprotein; WG, wellness group; SBP, systolic blood pressure. 
Table 4. Physiological Changes at Least 1 Year After Intervention Compared with the Day of the First Wellness Group (WG) Session (Treatment Group) or the Day of the Annual Physical (Comparison Group)

\begin{tabular}{lrcccc}
\hline Variable (n) & $\mathrm{n}$ & $\begin{array}{c}\text { Treatment } \\
(\text { mean, [SD]) }\end{array}$ & $\begin{array}{c}\text { Comparison } \\
\text { (mean [SD]) }\end{array}$ & $\begin{array}{c}\text { Raw Difference Between } \\
\text { Groups (Treatment- } \\
\text { Comparison) }\end{array}$ & $\begin{array}{c}\text { Difference Adjusting for } \\
\text { Baseline BMI }\end{array}$ \\
\hline Weight change (pounds) & 274 & $-13.21(20.6)$ & $+1.94(20.3)$ & $-15.15^{*}$ & $-12.53^{*}$ \\
BMI (kg/m ${ }^{2}$ ) & 268 & $-2.21(3.2)$ & $+0.30(3.3)$ & $-2.51^{*}$ & $-1.88^{*}$ \\
Systolic BP (mm Hg) & 277 & $-6.96(14.5)$ & $-1.13(14.0)$ & $-5.83^{*}$ & -1.78 \\
Diastolic BP (mm Hg) & 277 & $-5.70(10.0)$ & $-4.20(11.0)$ & -1.50 & 0.70 \\
Hemoglobin Alc (\%) & 86 & $+0.18(0.9)$ & $-0.01(0.7)$ & 0.16 & 0.13 \\
HDL (mg/dL) & 106 & $+2.81(7.5)$ & $+0.63(6.8)$ & 2.18 & 2.12 \\
LDL (mg/dL) & 96 & $-0.42(23.8)$ & $-5.00(22.6)$ & 4.58 & 2.58 \\
Total cholesterol (mg/dL) & 104 & $-3.23(24.0)$ & $-8.54(30.6)$ & 5.31 & 2.45 \\
Triglycerides (mg/dL) & 88 & $-34.27(70.9)$ & $-5.03(72.5)$ & -29.24 & -25.85 \\
\hline
\end{tabular}

${ }^{*} P<.05$, Independent samples $t$-test comparing change in treatment group to change in comparison group.

BMI, body mass index; BP, blood pressure; HDL, high-density lipoprotein; LDL, low-density lipoprotein; SD, Standard Deviation.

These 12 behaviors included reading food labels, eating fruits/vegetables, not overeating, getting more steps each day, eating more whole grains, managing stress more effectively, sleeping more, eating less beef, eating in front of screens less, eating more slowly, exercising more, and eating more homecooked meals. WG patients reported being more likely to create and maintain all 12 of these healthy behaviors.

Although WG patients were adopting and maintaining these 12 healthier behaviors, they were able to achieve sustainable weight loss as $61 \%$ of the WG patients lost clinically relevant weight $(>5 \%$ of their original body weight) and of these patients, $69 \%$ were able maintain at least half of their weight loss after 1 year. Patients who repeated the WG at least once had even better results as $83 \%$ of those who had clinically relevant weight loss maintained at least half of their weight loss.

Chart review revealed that in addition to increased weight loss (15 pounds more weight loss for WG patients than comparison patients after a year)

Table 5. Weight Loss (WG) of WG Patients

\begin{tabular}{|c|c|c|c|c|c|c|}
\hline & $\begin{array}{l}\text { Sample } \\
\text { Size } \\
\text { (n) }\end{array}$ & $\begin{array}{l}\text { Mean } \Delta \text { Weight } \\
\quad \text { (pounds) } \\
\text { During } \\
\text { Wellness Group } \\
\text { Program (WG)* }\end{array}$ & $\begin{array}{c}\text { Mean } \Delta \text { Weight } \\
\text { (pounds) After } \\
\text { Program } \\
\text { Completed }^{\dagger}\end{array}$ & $\begin{array}{c}\text { Number of Patients } \\
\text { Who Lost } \\
\text { Clinically Relevant } \\
\text { Weight }\end{array}$ & $\begin{array}{l}\text { Patients Who } \\
\text { Lost } \\
\text { Significant } \\
\text { Weight }(\%)^{\ddagger}\end{array}$ & $\begin{array}{l}\% \text { of Patients } \\
\text { Who Lost } \\
\text { Significant } \\
\text { Weight and } \\
\text { Maintained } \\
\geq 50 \% \text { of } \\
\text { Weight Loss }\end{array}$ \\
\hline All (WG) patients & 168 & -16.6 & 3.5 & 103 & $61 \%$ & $73 \%$ \\
\hline $\begin{array}{l}\text { All } W G \text { patients weighed } \geq 1 \\
\text { year after completing } W G \\
\text { program }\end{array}$ & 105 & -18.4 & 4.3 & 70 & $67 \%$ & $69 \%$ \\
\hline $\begin{array}{l}\text { WG Patients weighed } \geq 1 \\
\text { year after completing WG } \\
\text { program (only } 1 \text { program) }\end{array}$ & 60 & -16.1 & 7.0 & 35 & $58 \%$ & $54 \%$ \\
\hline $\begin{array}{l}\text { WG patients weighed } \geq 1 \\
\text { year after completing } W G \\
\text { program }(>1 \text { program })\end{array}$ & 45 & -21.6 & 0.6 & 35 & $78 \%$ & $83 \%$ \\
\hline $\begin{array}{l}\text { All WG patients weighed } \geq 3 \\
\text { years after completing } \\
\text { WG program }\end{array}$ & 50 & -18.5 & 3.3 & 35 & $70 \%$ & $71 \%$ \\
\hline
\end{tabular}

*Weight at last session of program minus weight at first session of program (first program if completed multiple programs).

${ }^{\dagger}$ Most up-to-date weight on record minus weight at last session of program (first program if completed multiple programs).

${ }^{\ddagger}$ At least $5 \%$ of weight at start of first WG.

${ }^{\S}$ Based on most up-to-date weight and weight at last session of program (first program if completed multiple programs). 
Figure 1. Patient weight change before and after WGs. The average total weight loss for a WG patient during the group (including first group and subsequent groups if they participated) was 20.1 pounds (168 patients, 3377 pounds). These 168 patients regained 1167 of the 3377 pounds between and after all their WGs. So, WG patients regained an average of 6.9 pounds (of the 20.1 pounds lost during the program).

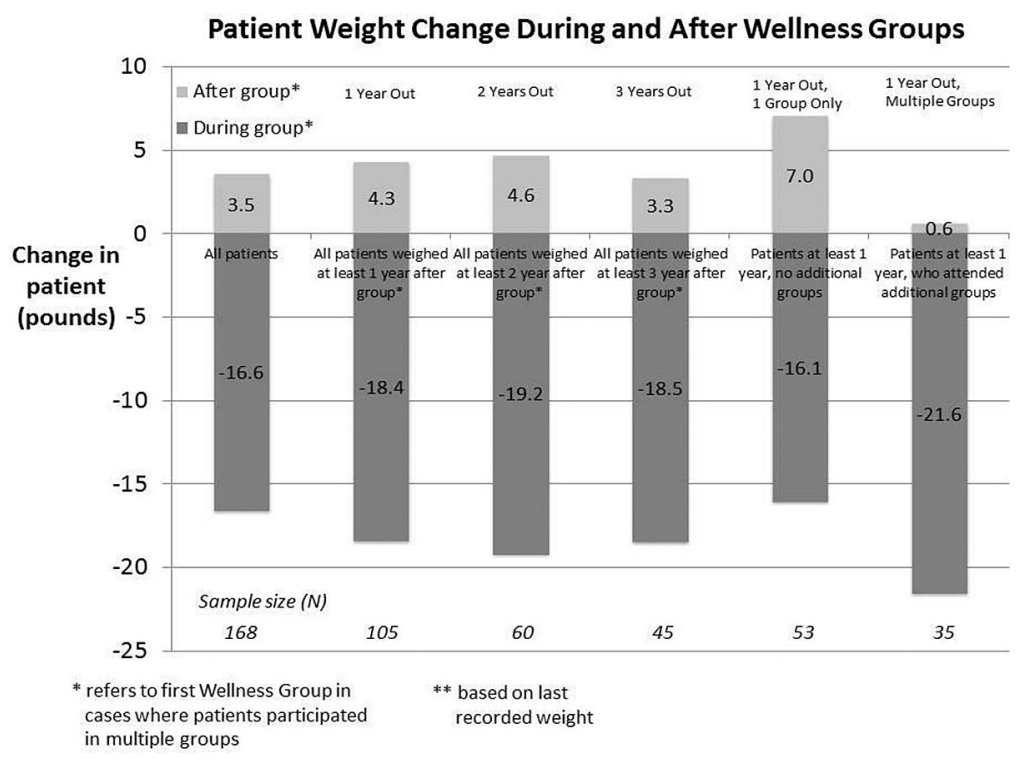

and BMI (2.51 BMI points less for WG patients than comparison patients after a year), the WG patients also had significantly lower systolic blood pressure than comparison patients. WG patients on average decreased their systolic blood pressure by approximately 7 points while comparison patients increased their blood pressure on average by more than 1 point. Other biomarkers such as glycohemoglobin, diastolic blood pressure, and lipids were slightly but not significantly more favorable in the comparison group. One possible explanation is that comparison patients may have been more likely to receive medication prescriptions for cholesterol and blood sugar values. Supporting this hypothesis is the fact that triglyceride values were favorable in the WG patients and triglycerides are less likely to respond to medications. The triglyceride difference was not statistically significant.

Although similar in age and sex breakdown, one might imagine that WG patients would be inherently different from the comparison patients in that WG patients each made the significant time and financial commitment to join the group with the goal of achieving long-term weight loss. As such, one might assume that WG patients were more motivated and, thus, more likely to experience greater behavioral change and weight loss than a group of TC patients. This is a potential limitation of this study.

This study is not a randomized control trial, and, as such, there is some inherent bias introduced by the different mindsets of the 2 patient groups. It was interesting however, that comparison patients actually reported twice as much effort with wellness behaviors in the year before the intervention than the WG patients, possibly suggesting that the comparison patients may have been motivated to lose weight. As such, it is unclear if either group had different levels of motivation.

It can be reasoned that the WG patients, by virtue of having been exposed to the group's curriculum, were more likely to know the "correct" answers to the survey questions and respond accordingly. For example, because they were taught the importance of reading food labels, they might be more inclined to say that they read more food labels now than they did before starting the group.

Although there is a chance that these 2 factors could have biased the results, it was somewhat reassuring that WG patients had significantly more declines in body weight, body mass index, and systolic blood pressure 1 year after the intervention than comparison patients, suggesting that the be- 
haviors that patients seemed to learn in the group translated to quantifiable results.

WG patients had a higher average $\mathrm{BMI}^{37}$ than comparison patients who had an average BMI of 34. The difference in starting BMI could have biased the results in all 3 phases of this study: patient survey, medical chart data, and weight loss over time. However, based on regression analysis, the effect of the intervention remained statistically significant, independent of the difference in BMI starting point.

Although weight loss seems attainable for many patients, the sustainability of weight loss is what seems elusive. Importantly, it is sustained weight loss over time that has an impact on weight-related illness. This novel WG model seemed to help a large number of patients achieve sustained results, which ultimately was the goal. Of the patients who achieved clinically relevant weight loss (at least 5\% of their weight), $69 \%$ maintained at least half of their weight loss 1 year after completing the group and $71 \%$ maintained at least half of their weight loss 3 years after completion. Of note, patients who had completed more than 1 of the 15 -session groups had even better results with $83 \%$ of those patients maintaining at least half of their clinically relevant weight loss. This data documenting sustained weight loss in WG patients is consistent with the survey data that indicated that WG patients were maintaining their healthy habits.

There are several limitations to this study. The retrospective design was inferior to a prospective analysis. The relatively low response rate of the comparison group surveys (53.3\%) may have introduced bias. One might speculate that comparison group nonresponders were different from those who did respond. It is possible that nonresponders did not complete the survey because they had less of a focus on wellness, although this could have positively skewed the wellness numbers of the comparison group thus falsely lowering the overall difference between WG patients and comparison patients. The fact that the 2 patient populations were not matched for starting BMI is an important limitation of this study. However, differences in weight loss were still statistically significant after regression analysis.

These results suggest that in this era of epidemic obesity and weight-related illness, the traditional 15-minute office visit and 1-on-1 patient care may be inadequate to make a difference in the long- term health of obese patients. Achieving long-term behavioral change in these patients may require the high levels of accountability and support generated in the group setting.

Future research could be aimed at measuring this support and accountability to determine whether it is directly correlating to behavioral change. It would also be interesting to understand why the effect sizes for some behaviors were so much larger than for other behaviors. In addition, generating financial models that elucidate the financial savings from long-term weight loss and behavioral change may motivate payers and health systems to increase infrastructure and financial support for WGs.

To see this article online, please go to: http://jabfm.org/content/ 30/6/715.full.

\section{References}

1. Ogden CL, Carroll MD, Kit BK, Flegal KM. Prevalence of childhood and adult obesity in the United States, 2011-2012. JAMA 2014;311:806-814.

2. Rippe J. Obesity: Prevention and treatment. Portland, OR: Book News Inc, 2012.

3. Barnett KG. Group medical visits: The future of healthcare? Glob Adv Health Med 2015;4:6-7.

4. Geller JS, Kulla J, Shoemaker A. Group medical visits using an empowerment-based model as treatment for women with chronic pain in an underserved community. Glob Adv Health Med 2015;4:27-60.

5. Tsai AG, Wadden T. Treatment of obesity in primary care practice in the United States: A systematic review. J Gen Intern Med 2009;24:10731079.

6. Douketis JD, Macie C, Thabane L, et al. Systematic review of long-term weight loss studies in obese adults: Clinical significance and applicability to clinical practice. Int J Obes 2005;29:1153-1167.

7. Appel LJ, Clark JM, Yeh HC, et al. Comparative effectiveness of weight-loss interventions in clinical practice. N Engl J Med 2011;365:1959-1968.

8. Jaber R, Braksmajer A, Trilling JS. Group visits: A qualitative review of current research. J Am Board Fam Med 2006;19:276-290.

9. Page C, Reid A, Andrews L, Steiner J. Evaluation of prenatal and pediatric group visits in a residency training program. Fam Med 2013;45:349-53.

10. Bendix J, Brower A. The benefits of sharing. Shared medical appointments can improve your patients' outcomes and your practice's efficiency. Med Econ 2011;88:68-71, 76.

11. Gallagher R, Kirkness A, Armari E, Davidson PM. Participants' perspectives of a multi-component, group-based weight loss programme supplement for 
cardiac rehabilitation: A qualitative study. Int J Nurs Pract 2012;18:28-35.

12. Jackson GL, Edelman D, Olsen MK, Smith VA, Maciejewski ML. Benefits of participation in diabetes group visits after trial completion. JAMA Intern Med 2013;173:590-592.

13. Cannon S, Lawry K, Brudell M, Rees R, Wenke R, Bisset L. Appetite for change: A multidisciplinary team approach to behavioral modification for weight management in a community health group setting. Eat Weight Disord 2016;21:661-668.

14. LeCheminant JD, Covington NK, Smith J, Lox CL, Kirk EP, Heden TD. Evaluation of a university-based community outreach weight management program. Popul Health Manag 2011;14:167173.
15. Kent L, Morton D, Hurlow T, et al. Long-term effectiveness of the community-based Complete Health Improvement Program (CHIP) lifestyle intervention: A cohort study. BMJ Open 2013;3(11): e003751.

16. Adolfsson B, Lundqvist-Persson C. Can lifestyle seminars and self-help groups contribute to sustained weight loss? J Community Med Health Educ 2016;6:439.

17. Edelman D, McDuffie JR, Oddone E, et al. Shared medical appointments for chronic medical conditions: A systematic review. Washington, DC: Department of Veterans Affairs (US); 2012. Available from: http://www.ncbi.nlm.nih.gov/ books/NBK99785/ 